\title{
Embraer, história, desenvolvimento de tecnologia e a área de defesa
}

\author{
Armando Dalla Costa*
}

Elson Rodrigo de Souza-Santos ${ }^{* *}$

RESUMO - Nas últimas décadas o Brasil construiu de forma proposital e como política de Estado a indústria aeroespacial tendo como líder a empresa mais importante, Embraer. Inicialmente, a indústria tinha como objetivo abastecer o setor de defesa brasileiro e proporcionar autonomia no ramo aeroespacial. Mesmo a Embraer na era pré-privatização tinha como foco e base de apoio para o desenvolvimento de produtos o abastecimento das Forças Armadas (FA's) brasileiras e a exportação. Entretanto, com a crise da década de 1980 seguida da privatização ocorrida em 1994, a Embraer passa a focar nas exportações, especialmente no segmento de aviação regional e executiva, ambos em franco crescimento e com pouca competição. Apesar da sua área de defesa ter crescido, diversificado e sofisticado, perdeu importância relativa, mas ainda assim é fundamental para o desenvolvimento de tecnologia e para a saúde financeira.

Palavras-chave: Indústria aeroespacial. Embraer. Área de defesa.

\section{INTRODUÇÃO}

A Embraer cristaliza uma política de Estado com mais de meio século objetivando a construção da capacidade brasileira de desenvolver equipamentos aeroespaciais entendidos como envolvendo a área aeronáutica (fabricação de aeronaves, componentes e equipamentos), defesa (equipamentos de uso militar) e espacial (equipamentos e componentes usados no espaço). Segundo a Associação das Indústrias Aeroespaciais Brasileiras (AIAB, 2010) o Brasil tem atualmente a maior indústria aeroespacial do hemisfério sul, constituída não apenas por uma empresa, mas por um conjunto que permite ao país ser competitivo a nível internacional. A Embraer nasceu em 1969 como estatal a fim de cristalizar a política de construção das capacidades aeroespaciais do núcleo de desenvolvimento capitalizado pela CTA (Centro Tecnológico da Aeronáutica) e ITA (Instituto Tecnológico da Aeronáutica). Quando foi privatizada em 1994 o foco passou a ser a aviação civil, mais especificamente o ainda inexplorado nicho de jatos regionais, o que proporcionou oportunidades enormes de crescimento, transformando a Embraer em uma das maiores empresas aeroespaciais do mundo com cerca de 5.000 aviões

\footnotetext{
*Doutor em história econômica pela Universidade de Paris III (Sorbonne Nouvelle). É professor do Departamento de Economia e do Programa de Pós-Graduação em Desenvolvimento Econômico da Universidade Federal do Paraná. Coordenador do Núcleo de Pesquisa em Economia Empresarial. Endereço eletrônico: ajdcosta@ufpr.br. ${ }^{* *}$ Graduado em economia pela Universidade Federal do Paraná, e membro do Núcleo de Pesquisa em Economia Empresarial - NUPEM. Bolsista do CNPq. Endereço eletrônico: elson129@gmail.com.
} 
operados em 88 países, maior exportadora brasileira entre 1999 e 2001, segunda maior nos três anos seguintes, contando com uma força de trabalho de 16 mil empregados, cerca de 95\% baseados no Brasil.

Na história da Embraer a área de defesa teve e tem enorme importância para a construção das capacidades tecnológicas da companhia. Em grande parte isso se deve a sua origem quando buscou materializar no pensamento estratégico brasileiro a necessidade de desenvolver tecnologia e produtos aeroespaciais, especialmente aviões, vistos como estratégicos desde a década de 1930 (BOTELHO, 1999; FORJAZ, 2003; GOLDSTEIN, 2002). Atualmente a divisão de defesa da Embraer é responsável por mais de 50\% da frota da força aérea brasileira e cerca de 20 forças aéreas no exterior. A linha de produtos abrange versões de aviões de inteligência utilizando as plataformas de jato regional ERJ 145, aviões de treinamento/ataque como o Super Tucano e, recentemente, a implementação do projeto de cargueiro militar KC-390 que em muito difere das características da aviação civil. Além da implementação de projetos como integração de redes de inteligência, modernização de meia vida de aviões (tais como F5 de origem norte-americana e AMX fabricado pela própria empresa) e o fornecimento de peças (por exemplo, para modelos de helicópteros da norte-americana Sikorsky).

Entre as características da área de defesa da Embraer três se destacam. A primeira é que no geral o faturamento da área de defesa é relativamente baixo em relação ao total da empresa. A segunda leva a firma a buscar nichos de mercado em que exista pouca concorrência e onde seja possível integrar equipamentos e componentes de diversas origens com criatividade em nome de superar grandes desenvolvimentos em tecnologia, permitindo que a empresa faça frente aos gigantes do setor como a norte-americana Boeing e a europeia EADS. Por último, recorrerem a parcerias com empresas nacionais, internacionais e financiamento do Estado brasileiro em busca de viabilizar o produto, reduzir riscos e custos. Assim, mesmo pós-privatização, a área de defesa da Embraer cresceu, diversificou e sofisticou os seus produtos sendo importante para as finanças e aquisição de know-bow para projetos civis.

O trabalho busca explorar a importância da área de defesa da Embraer. Para isso está dividido em três partes. A primeira apresenta a visão geral sobre a Embraer como uma empresa de sucesso no setor aeronáutico e uma das grandes do mundo. A segunda foca na área de defesa da Embraer construída ao longo de sua história e que obteve sucesso nos segmentos em que atua, sendo uma parceira interessante e até competidora para as grandes empresas de defesa do mundo. Por último são apresentados exemplos de projetos de sucesso e as possibilidades futuras. 


\section{ORIGEM E HISTÓRIA DA EMBRAER}

A Embraer - Empresa Brasileira de Aeronáutica S.A. - é uma das maiores empresas aeroespaciais do mundo. Em sua história produziu cerca de 5 mil aviões, operados em 88 países (EMBRAER, 2010). Fundada em 1969 como estatal de capital misto, cristalizava o projeto nacional de desenvolvimento e domínio da tecnologia aeroespacial originada na década de 1930, apontada como essencial do ponto de vista militar. Após a privatização em 1994 passou por uma reestruturação e o foco de negócio voltou-se para o mercado civil, especialmente dos nichos inexplorados pelas grandes empresas do setor como Boeing e Airbus. O foco passou a ser a demanda das companhias regionais e menores, operando com mais baixo custo, sobretudo nos Estados Unidos e na Europa. O resultado é que a Embraer foi a maior exportadora brasileira entre os anos de 1999 e 2001, a segunda maior nos anos de 2002, 2003 e 2004, transformando-se na quarta maior do setor de aviação civil do mundo. Esses fatos levam autores como o indiano Krishnan (2002) ver o sucesso da Embraer e o modelo adotado para o setor aeroespacial no Brasil como inspiração para a Índia.

A fundação da Embraer no fim da década de 1960 coroa um projeto que remetia a década de 1930, encampado principalmente pelos militares da então Força Aérea do Exército e da Marinha, que viam o domínio da tecnologia aeronáutica como fundamental para o Brasil¹. Segundo Botelho (1999), a Embraer foi antecedida pelo CTA fundado na década de 1940 como um centro de desenvolvimento tecnológico, seguido pelo ITA na década de 1950 e objetivava criar uma massa crítica de engenheiros para dar curso aos projetos aeroespaciais. Para Forjaz (2003) o ITA e o CTA “tornaram-se irradiadores para a fixação de tecnologias e suporte para a criação de inúmeras empresas”, principalmente formadas na região do Vale do Paraíba no estado de São Paulo. Assim, na década de 1970 o Brasil construía o tripé que daria sustentação ao desenvolvimento de tecnologias aeroespaciais: o CTA como centro de pesquisas; o ITA responsável pelo desenvolvimento do corpo técnico; e a Embraer como empresa líder na criação de produtos e organização das demais firmas locais e regionais.

Nos primeiros anos da Embraer, Ozires Silva (1998), engenheiro formado no ITA e que participou do grupo que a criou, relata que a empresa decidiu optar pela cooperação com as concorrentes estrangeiras através da coprodução e licenciamento de produtos para penetrar no mercado sem excessiva dependência tecnológica. É o caso de um dos primeiros aviões produzidos sob licença pela Embraer, o Aermacchi MB-326, denominado no Brasil como Xavante. O avião era um jato de treinamento/ataque militar concebido pela italiana Macchi no fim da 1 A FAB - Força Aérea Brasileira nasceu apenas em 1941. Em países como os Estados Unidos a Força Aérea desvinculada das outras forças se firmou após a Segunda Guerra Mundial, mas em outros como a Grã-Bretanha a força aérea nasceu junto com a utilização do avião. 
década de 1950, de baixo custo de operação, produção, robusto e versátil, adquirido em grandes quantidades pela FAB. Ao mesmo tempo começavam a nascer os primeiros aviões concebidos pela Embraer em conjunto com o CTA e ITA, como o Bandeirantes (avião de transporte pequeno e turboélice) e o Tucano (avião de treinamento/ataque a turboélice). Ambos financiados e adquiridos pelo Estado brasileiro.

Além do mercado interno, formado basicamente pelo Estado, como observa Dagnino (1993), o mercado externo ganhava importância para viabilizar a produção de aviões no Brasil. Para isso a empresa passou a buscar certificados internacionais e penetrar em nichos propensos a aceitar produtos. No mercado civil pode ser citado o Bandeirantes como plataforma de transporte competitivo frente as rivais norte-americanas Beech e Fairchild, conquistando um terço do mercado norte-americano de transporte. O mesmo ocorreu na década de 1980 quando a Embraer conseguiu vender o tucano como avião de treinamento para outras forças aéreas, especialmente a britânica e francesa, duas das mais importantes do mundo. Em ambos os casos a firma apresenta como vantagem produtos baratos, soluções inovadoras. Simultaneamente, a Embraer com o apoio do Estado passou a implementar projetos mais sofisticados como o AMX (avião de ataque/treinamento a jato) em parceria com a Itália e, no fim da década de 1980, o embrião do projeto dos aviões de transporte regional.

Entretanto, na década de 1980, como observa Goldstein (2002), começa a crise da Embraer devido as condições macroeconômicas nacionais desfavoráveis como a redução da capacidade e interesse do governo em financiar seus projetos e continuar adquirindo produtos. Além do mais na administração Collor e Franco (1990 - 1994) os ajustes estruturais, a nova filosofia de "emagrecimento do Estado" levaram a onda de privatizações de empresas anteriormente consideradas estratégicas. Nesse contexto a Embraer foi privatizada em dezembro de 1994 após passar pela reestruturação com o adiamento de projetos importantes como o jato regional ERJ 145. O controle acionário permaneceu em mãos nacionais através dos fundos de pensão Previ (20\%), Sistel (20\%) e Companhia Bozano, Simonsen (20\%), além de sócios minoritários como a EADS - France e Dassault e a "golden share" do Estado brasileiro a fim de vetar negócios que potencialmente prejudiquem a segurança nacional.

A partir da privatização a Embraer passa pela reestruturação financeira e investe na consolidação do projeto de jatos regionais tendo como líder o modelo ERJ 145. Porque, como observa Goldstein (2002), o mercado internacional para a aviação regional cresceu cerca de 50\% entre 1998 e 1999, especialmente nos Estados Unidos. O competidor do mercado de jatos regionais era basicamente a canadense Bombardier. Assim, a Embraer conseguiu se aproveitar da oportunidade e, como consequência, as exportações de jatos regionais totalizavam $90 \%$ do 
total. A Embraer (2010) é uma das maiores empresas aeroespaciais do mundo e a maior do Brasil. Em mais de 40 anos produziu cerca de 5.000 aviões operados em 88 países.

A partir de 2004 nasce a nova família de jatos regionais com as plataformas Embraer 170/190. A Estrutura atual da Embraer visa gerar valor para seus acionistas, através da plena satisfação de seus clientes do mercado aeronáutico global. Por geração de valor entende-se a maximização do valor da Empresa e a garantia de sua perpetuidade, com integridade de comportamento e consciência social e ambiental. A Empresa deve se concentrar em três áreas de negócio e mercados: Aviação Comercial; Aviação Executiva; Mercado de Defesa.

TABELA 1 - EMBRAER EM NÚMEROS: 2007-2009

\begin{tabular}{l|r|r|r}
\hline & \multicolumn{1}{c|}{$\mathbf{2 0 0 7}$} & $\mathbf{2 0 0 8}$ & \multicolumn{1}{c}{$\mathbf{2 0 0 9}$} \\
\hline Receita Líquida (em R\$ milhões) & 9.994 & 11.747 & 10.813 \\
Lucro Líquido (em R\$ milhões) & 1.185 & 429 & 895 \\
Entrega de Aeronaves & 169 & 204 & 244 \\
Ordens Firmes (em US\$ bilhões) & 19 & 21 & 17 \\
Investimento em P\&D (em R\$ milhões) & 413 & 482 & 353 \\
Ativo Total (em R\$ milhões) & 15.476 & 21.499 & 15.946 \\
Patrimônio Líquido (em R\$ milhões) & 4.638 & 5.971 & 5.021 \\
Empregados & 23.734 & 23.509 & 16.853 \\
\hline
\end{tabular}

FONTE: Embraer (2010b) e quadro construído pelos autores.

Nos últimos três anos (ver tabela 1) aparentemente a Embraer reduziu seu tamanho e buscou reestruturar a fim de se adaptar a nova realidade provocada pela crise de $2008 \mathrm{com}$ a redução da oferta de crédito e da demanda por voos, especialmente no Estados Unidos que são o seu principal mercado. Em função disso o número de empregados foi reduzido de 23 mil para 16 e os pedidos firmes de 19 para 17 bilhões de dólares. Apesar da crise as entregas de aeronaves cresceram para atender as encomendadas de antes da crise e estarem em processo de produção. Lembrando que o ciclo de produção de um avião civil costuma levar meses (até anos) para ser completado e passar pelos testes de qualidade e segurança.

A receita da Embraer tem como grande contribuição a área de aviação comercial (ver gráfico 1), seguida de uma divisão quase equânime entre as aéreas de serviços aeronáuticos, defesa e aviação executiva. Em outras palavras, isso quer dizer que a Embraer tem como sustentáculo do seu negócio a aviação regional. O que é potencialmente problemático porque a demanda por aviões sofre os revezes da economia mundial. Por exemplo, na crise de 2008, a Embraer foi obrigada a buscar alternativas e apoio do Estado para não entrar em uma situação difícil. Diferente de outras grandes empresas aeroespaciais do mundo como a norte-americana Boeing que junto com a europeia AirBus disputa a liderança na produção de aviões comerciais, mas detém uma área de defesa e contratos estatais que minimizam os efeitos das variações no 
mercado de aviação civil.

GRÁFICO 1 - ORIGEM DA RECEITA DA EMBRAER POR ÁREA (DADOS DO SEGUNDO TRIMESTRE DE 2010)

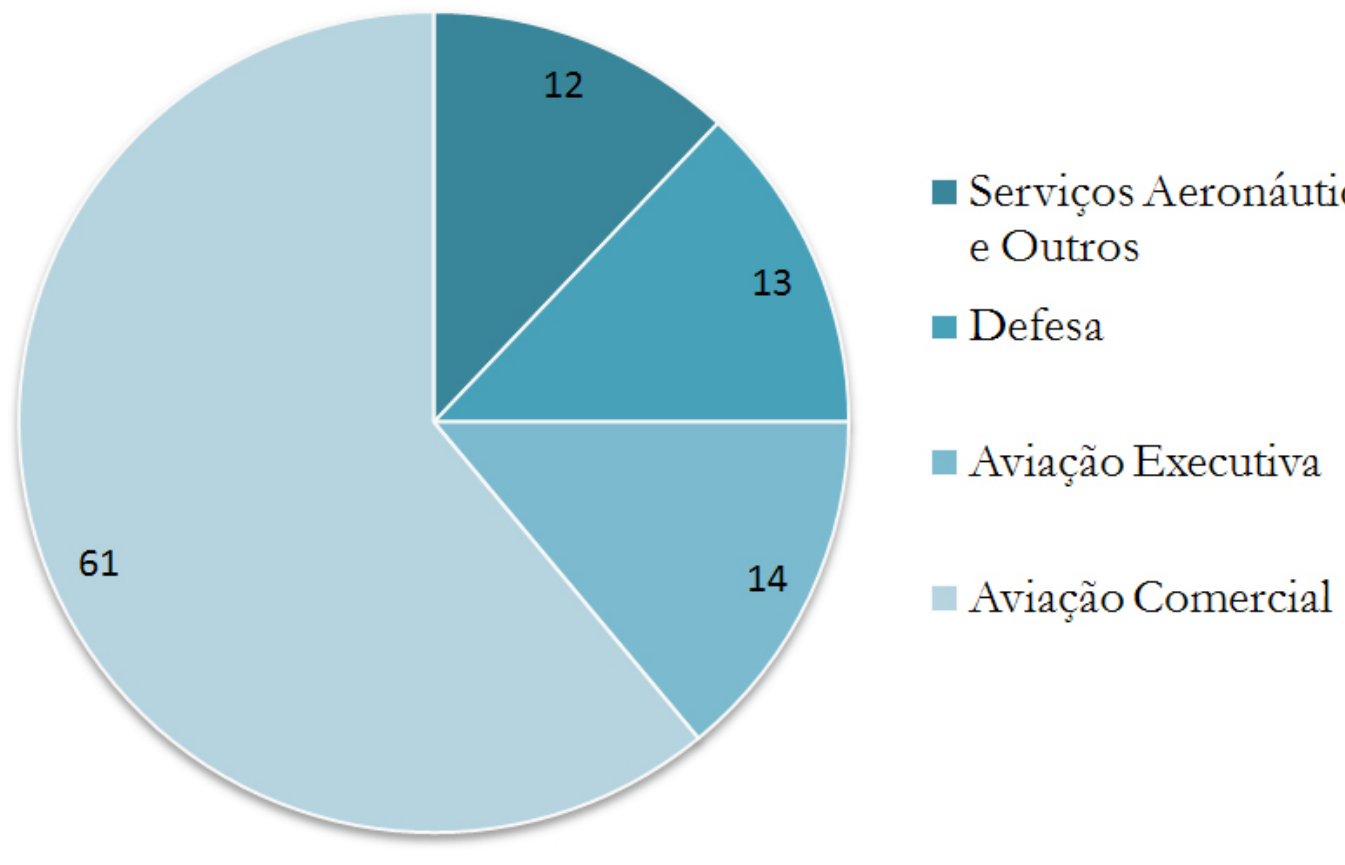

FONTE : Embraer (2010).

No caso do Brasil a forma do Estado dar suporte a Embraer e a rede de fornecedores da indústria aeroespacial é basicamente através do BNDES e aquisição de equipamentos destinados as FA's. Por exemplo, a crise foi decisiva para impulsionar o projeto de desenvolvimento do cargueiro militar KC-390 através de fundos do BNDES e governo federal como também, na década de 1990, a aquisição de aviões Super Tucano. É claro que a capacidade de ação do Estado brasileiro é menor do que nos Estados Unidos ou Europa, mas existe e serve como um impulsionador do desenvolvimento de novos produtos na área civil e manutenção da saúde financeira das empresas do setor.

\section{3 ÁREA MILITAR}

A área de defesa da Embraer é tão ou mais antiga que a própria empresa. A Embraer em si foi criada para cristalizar e liderar o processo de desenvolvimento de tecnologias aeroespaciais. Os arquitetos do desenvolvimento do pólo aeroespacial de São José dos Campos visavam o domínio de tecnologia aeroespacial de uso militar visto como estratégico. Esta envolve não só o desenvolvimento e produção de aviões de combate em si, mas a produção sob licença, adaptações, manutenção, desenvolvimento de projetos de modernização, homologação e introdução 
de novos equipamentos, desenvolvimento de softwares, materiais, equipamentos espaciais.

Olhando para as grandes firmas aeroespaciais observa-se que a maioria possui departamentos de defesa proporcionalmente grandes, que lideram projetos considerados estratégicos e envolvem grandes somas de dinheiro. Não que as aeroespaciais importantes sejam apenas as que fabricam aviões, pelo contrário, existe uma infinidade de grandes e importantes empresas especializadas em componentes e equipamentos como radares e motores. Ao mesmo tempo, é comum que as mesmas firmas mantenham a competitividade no setor civil utilizando - e muito - a tecnologia e ensinamentos adquiridos para a utilização em produtos civis, manter a sua competitividade devido a produção de tecnologias. Por exemplo, a norte-americana Raytheon produz radares e equipamentos de sistemas eletrônicos para aeronaves com funções militares a partir de radares civis e de controle de trafego aéreo, utilizando tecnologias duais e o conhecimento adquirido nos projetos militares. O mesmo ocorre com uma possível concorrente da Embraer, a Sukhoi, tradicional fabricante de caças russa que recentemente lançou o jato regional Superjet 100 utilizando a tecnologia e conhecimento adquirido em projetos militares, mas tentando adequar aos custos, durabilidades e manutenção requeridos pelo mercado civil mundial.

$\mathrm{Na}$ Embraer merece destaque a divisão de defesa dentro da política nacional para obter autonomia no desenvolvimento de tecnologia aeroespacial. Marques e Oliveira (2009) enfatizam que entre 1960 e 1980 o investimento em desenvolvimento da Embraer era, sobretudo, voltado para o desenvolvimento de equipamentos para criar equipamentos voltados ao uso militar, mas que permitiu adquirir conhecimento e capacidades tecnológicas. Nesse intervalo de tempo, três projetos ganham destaque:

- Xavante: no fim da década de 1960 a FAB passou a estudar a renovação da frota de treinadores e criar uma frota de ataque ao solo. Ao mesmo tempo em que possibilitasse ser montado no Brasil pela Embraer com progressiva nacionalização. O escolhido foi o italiano Aermacchi MB-326G, fabricado pela Macchi, projeto da década de 1950, mas adequado a necessidade. A Aeronáutica contratou inicialmente a aquisição de 112 exemplares, mas o número total chegou a 167 , sento que o total produzido foi de 182 com o excedente exportado para o Paraguai e Togo.

- Tucano: nasceu da necessidade de um treinador básico a hélice para a FAB, de baixo custo e a turbo-hélice na década de 1970. O projeto foi apresentado a FAB no fim de 1970 como EMB 312 sendo projetado pela Embraer. Em 1980, o projeto é aceito, batizado de Tucano e são encomendadas 118 aeronaves. Pouco depois outros países, como Honduras e Egito, se interessaram pelo projeto. Porém o marco foi a vitória na concorrência no Reino Unido, onde o Tucano foi modificado com o auxílio da empresa irlandesa Short Brothers PLC para atender 
os requisitos britânicos. Em 1991 a França adquiriu 80 aeronaves Tucano. Atualmente opera em 15 forças aéreas do mundo.

- AMX: na década de 1970 a Embraer estudava a viabilidade de um avião supersônico de treinamento e, principalmente, voltado para a função de ataque, que fosse superior ao Xavante e atendesse as necessidades crescentes da FAB. Na mesma época os italianos buscavam uma aeronave parecida abrindo caminho para a associação entre Brasil-Itália envolvendo a Embraer e as italianas Aeritália (hoje Alenia) e Macchi na década de 1980. A Embraer ficou responsável pelas asas do avião, além de desenvolver os sistemas hidráulicos, elétricos e eletrônicos, enquanto que a fuselagem seria de fabricação italiana. O primeiro protótipo brasileiro foi apresentado em 1985 e, em 1989, ocorreu a primeira entrega totalizando 54 aeronaves, mais cerca de uma centena italianas.

Os dois primeiros projetos constituem uma trajetória natural de busca de aquisição de tecnologia estrangeira seguida da tentativa de transformá-la em novos produtos. Ambos se prestaram ao seu fim. Entretanto o AMX pode-se chamar de um enorme fracasso comercial, mas grande sucesso em aquisição e desenvolvimento de tecnologia de caças a jato. $\mathrm{O}$ fracasso provém de não ter sido comercializado na quantidade esperada devido ao fim da guerra fria e a disponibilidade de caças superiores usados a custos menores. Assim, os custos de desenvolvimento do AMX se tornaram proporcionalmente grandes dado o pequeno número de aeronaves produzidas. Além do mais as versões brasileiras foram ceifadas de equipamentos sofisticados devido a redução de custos e dificuldades financeiras do país. No âmbito tecnológico o AMX permitiu a Embraer e a suas parcerias entender como funciona o projeto de um avião a jato. Fundamental para o projeto do jato regional ERJ 145 iniciado em 1989.

No decorrer da década de 1990 embarca em três projetos chaves:

- Desenvolvimento dos aviões de inteligência: a implantação do projeto SIPAM / SIVAM (Sistema de Proteção da Amazônia / Sistema de Vigilância da Amazônia) constituindo um conjunto de radares, satélites e sistemas de sensoriamento remoto da região amazônica. Parte do programa previa a aquisição de aviões de inteligência, mas também considerava a possibilidade de dotar a FAB de sistema de inteligência capaz de colocá-lo em pé de igualdade com a estrutura encontrada em países de primeiro mundo. Para isso a Embraer formulou o projeto de transformar o ERJ 145 em bases de inteligência móveis, mais baratos que os usados pela OTAN e mais flexíveis devido ao menor tamanho. Entregues no fim da década de 1990, despertaram o interesse de Grécia e México, como também, recentemente da Índia.

- Mirage2000BR: o programa de reaparelhamento da FAB iniciado em 2000 vislumbrou a oportunidade da Embraer produzir e absorver tecnologias duais de um caça conside- 
rado avançado de origem francesa do modelo Mirage2000, apoiada na pequena porcentagem de ações que a Dassault e EADS detinham da Embraer (GOLDSTEIN, 2002). O projeto foi adiante apesar de, na época, ser considerado ultrapassado e estar em fim de linha de produção na França. Entretanto, mesmo com a pressão da Embraer, não houve compra direta, mas sim uma concorrência internacional conhecida como FX no começo da década de 2000. Sem resultados ou decisões foi cancelado em 2003.

- Super Tucano: foi um redesenho do Tucano em busca de dar maior capacidade de ataque ao solo e antiguerrilha, especialmente para ser usado no SIVAM, sendo um avião reforçado com maior poder de fogo, alcance e resistência. Apesar de ser turbo-hélice conta com tecnologia equivalente de um avião atual. A história dessa versão começa na década de 1980, mas em 1993 foi entregue a primeira unidade a FAB que encomendou mais de 100 e continuam sendo entregues até hoje. É um modelo único no seu segmento e está a frente de aviões de treinamento adaptados a missão antiguerrilha o que lhe proporciona grande potencial no mercado internacional. Tanto que vendas foram fechadas para Chile, Colômbia, Equador, Canadá e República Dominicana.

Finalmente, o marco para a evolução dos projetos na área de defesa da Embraer foi o projeto e execução de modernização dos cerca de 50 caças F5 Tiger II da FAB em conjunto com a israelense Elbit (subcontratada da Embraer) para auxílio e transferência de tecnologia. Não que a modernização dos caças F5 não tenha sido feita por outros países, mas o projeto da Embraer é um novo avião customizado para a FAB. Recentemente, a Embraer desenvolve o projeto de modernização dos AMX (EMBRAER, 2010).

$\mathrm{Na}$ área militar o novo grande projeto da Embraer é um cargueiro militar para 19 toneladas. Apresentado em 2007 durante a sexta edição da LAAD (Latin America Aerospace and Defense), a maior e mais importante feira voltada às Forças Armadas e às indústrias de defesa da América Latina. Dois anos depois, em cerimônia realizada durante a LAAD, no Rio de Janeiro, a Embraer fechou contrato com a Força Aérea Brasileira (FAB) para o programa da aeronave de transporte militar e reabastecimento, cuja aeronave passou a ser denominada KC-390 (EMBRAER, 2010). A ideia dessa aeronave é ocupar um mercado ocidental que tem apenas um competidor, o Hércules C-130, produzido pela norte-americana Lockheed Martin e o projeto original data da década de 1950. Além do mais os países que utilizam versões usadas (Brasil, por exemplo) estão chegando ao fim de sua vida útil e não há tantos modelos usados como no passado no mercado internacional. A opção de adquirir novos modelos do Hércules seria cara, o competidor mais próximo é o AirBus A-400, mas com maior custo e maior capacidade de carga. Para as forças aéreas acostumadas ao padrão ocidental o uso de aviões de 
transporte russos ou orientais é praticamente descartada porque o custo de adaptação é elevado. Assim, potencialmente o mercado para o KC-390 é atrativo, não apenas para forças aéreas como mercado civil de transporte de cargas.

Entre as características que diferenciam o KC-390 do seu principal competidor destacam-se: (i) ser a turbina e consequentemente mais rápido e voar mais longe; (ii) ter uma arquitetura de projeto mais moderna visando reduzir custos e tempo de manutenção; e (iii) principalmente, utilizar tecnologias e equipamentos conhecidos e disponíveis no mercado para conceber o avião, assim, reduzindo custos e riscos. O projeto ainda é embrionário e deve voar na próxima década.

\section{CONCLUSÃO}

Em forma de conclusão, destacam-se três aspectos na trajetória da Embraer e em sua atuação em novas tecnologias para a aviação militar. O primeiro é a inter-relação entre Escola (ITA), empresa (Embraer) e governo. No que se refere à escola, o ITA deu uma contribuição essencial na formação dos engenheiros que se constituíram no saber acumulado que permitiu a mão-de-obra qualificada que sustentou, desde o início (MORAIS, 2006) a trajetória da firma. Esta viabilizou-se porque contou com a parceria do governo, com destaque especial para seu início, quando os aparelhos produzidos eram feitos sob encomenda para atender a demanda do Ministério da Aeronáutica.

O segundo aspecto é a permanente busca de construir novos aparelhos, tecnologicamente competitivos para atender demandas de nichos de mercado. No que foi o foco do texto, isto é, em relação às novas tecnologias militares, tratou-se de verificar como a Embraer adaptou permanentemente seus aparelhos para atender tanto as necessidades de forças aéreas de países "periféricos" como o Chile, Brasil, entre outros e "centrais", como a França e Inglaterra. Obviamente, as exigências destes últimos em termos de qualidade e performance dos produtos são muito diferenciadas. Analisando a trajetória da Embraer (SILVA, 2008) fica claro que uma empresa nacional, desde que bem estruturada a partir do tripé: inovação, $\mathrm{P} \& \mathrm{D}$ e novos produtos tem condições de atender a demanda internacional mais exigente.

O terceiro aspecto que chama atenção é a relação de setores industriais com o governo. Na Embraer estabeleceu-se uma parceria bem sucedida, que atendeu tanto as necessidades da empresa pública e depois privada como as demandas da Força Aérea. A questão que surge é por que não se conseguiu instituir um arranjo político-institucional-empresarial que viabilizasse a constituição de empresas automobilísticas com chances de atender tanto o mercado interno como as exportações? 


\section{REFERÊNCIAS}

AIAB. A Indústria Aeroespacial Brasileira. Disponível em: <http://www.aiab.org.br/portugues/ index.php?option $=$ com_content\&task=view\&id=13\&Itemid=26>. Acesso em: 20/08/2010.

BOTELHO, A. J. J. Da Utopia Tecnológica aos Desafios da Política Científica e Tecnológica: o instituto tecnológico da Aeronáutica $(1947$ - 1967). Revista Brasileira de Ciências Sociais, v.14, n. 39, p.139-154, fev. 1999.

DAGNINO, R. Competitividade da Indústria Aeronáutica. Brasília: Ministério da Ciência e Tecnológica/Financiadora de Estudos e Projetos - FINEP/Programa de Apoio ao Desenvolvimento Científico e Tecnológico, 1993.

EMBRAER. Embraer. Disponível em: <http://www.embraer.com.br/portugues/content/ empresa/profile.asp>. Acesso em: 21/08/2010.

EMBRAER. Embraer: relatório anual 2009. Disponível em: <http://www.embraer.com.br/ relatorios_anuais/relatorio_2009/portugues/index.html>. Acesso em: 20/08/2010.

EMBRAER. Centro Histórico Embraer. Disponível em: <http://www.centrohistoricoembraer.com.br/Default.htm?version=5.0\#HistoriaDasAeronaves $>$. Acesso em: 20/08/2010.

FORJAZ, M. C. S. As Origens da Embraer: o projeto estratégico da aeronáutica. EAESP/ FGV/NPP - Núcleo de Pesquisas e Publicações, 2003. Relatório de Pesquisa, nº22.

GOLDSTEIN, A. Embraer: from national champion to global player. Cepal Review, n. 77, p. 97-115, ago. 2002.

KRISHNAN, R. Embraer's Emergence as a Leading Aircraft Company: Lessons for Indian High Tech Enterprise. Disponível em: <www.iimb.ernet.in/ rishi/nal.PDF>. Acesso em: 20/08/2010.

MARQUES, R. A.; OLIVEIRA, L. G. Sectorial System of Innovation in Brazil: reflections about the acumulation of technologial capabilities in the aeronautic sector. In: MALERBA, F.; MANI, S. (Orgs.). Sectorial Systems of Innovation and Production in Development Countries: actors, structure and evolution. Northampton: Edward Elgar Publishing, p. 156207, 2009 .

MORAIS, F. Montenegro. As aventuras do marechal que fez uma revolução nos céus do Brasil. São Paulo: Planeta, 2006.

SILVA, O. Nas Asas da Educação: a trajetória da EMBRAER. Rio de Janeiro: Campus, 2008.

SILVA, O. A Decolagem de Um Sonho. A História da Criação da Embraer. São Paulo: Lemos, 1998. 
